\title{
Effectiveness of P-Delta Analysis in the Design of Tall Slender RC Structures
}

\author{
Saranya S. Pillai ${ }^{1 \mathrm{a} *}$, Namitha Chandran ${ }^{2}$ \\ ${ }^{1}$ PG Scholar, Structural Engineering, SBCE \\ ${ }^{2}$ Assistant Professor, Department of Civil Engineering, SBCE
}

\begin{abstract}
As urbanization increases worldwide, the available land for buildings is becoming scarcer and scarcer, and the cost of land is becoming higher and higher. Thus the popularity of high rise structures are increasing day by day to accommodate growing population in metropolitan cities. The present study focusses on the effectiveness of p-delta analysis in the design of tall slender reinforced concrete structures. A study on the stability of tall structures to lateral forces with and without considering p-delta effects is carried out in the present investigation The building models with different storey heights have been analysed to investigate the maximum response in the building in terms of displacement, moment and shear forces. The analysis of multi-storeyed RC building have been done using ETABS 2015 Structural analysis software.
\end{abstract}

Keywords: Tall slender RC structure, Linear static analysis, P-Delta analysis, ETABS, Displacement

\section{Introduction}

A tall building is defined as the one in which the structural system is adopted such that to make it sufficiently economical and also to resist lateral forces due to wind or earthquake within the prescribed criteria for strength, drift and comfort of the occupants. Tall buildings are the most structures that requires stability because it consists a lot of frame structure with different width and height. Generally, structural designers are prone to use linear static analysis, which is also known as first order analysis, to compute design forces, moments and displacements resulting from loads acting on the structure. First order analysis is performed by assuming small deflection behaviour where the resulting forces, moments and displacements take no account of the additional effect due to deformation of the structure under vertical loads prior to imposing lateral loads. In the traditional first order analysis of structures, the effects of change in the structure actions due to structure deformations are neglected. However, when a structure deforms, the applied loads may cause additional actions in the structure that are called second order or p-delta effects.

\subsection{P-Delta Effect}

P-Delta is a non-linear effect that occurs in every structure where elements are subject to axial loads. It is a genuine effect that is associated with the magnitude of applied axial load ' $\mathrm{P}$ ' and displacement 'delta'. If a P-Delta affected member is subjected to lateral load then it will be proneto more deflection which could be computed by P-Delta analysis not the linear static analysis. Although the development of knowledge and advancement of technology is quite advanced today, there are a very few practical experimental studies on the P-Delta effects of the structure. The most used structural analysis for reinforced concrete design is linear static analysis, where P-Delta effect is omitted which is very important to include in analysis and design phase. Because of that, high rise structures may show potential vulnerability against lateral loads. P-Delta analysis may bring the second order loading effects in the structure and design the structure with its effects. This analysis is no more a matter of time consuming paper work but easy and simple which could be performed by engineers and researchers. Nowadays many software have the capability to do analysis and design with P-Delta effects.

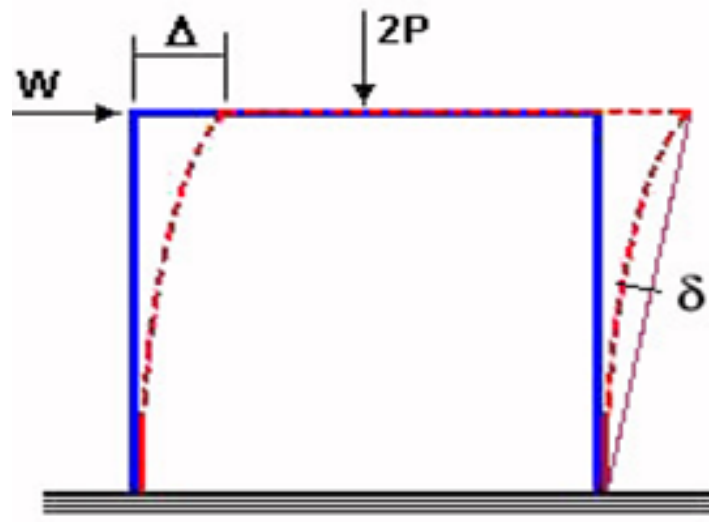

Figure 1: P-Delta effect

\subsection{Importance of Study}

In the modern era, the demand of tall structures are greater than earlier due to the provision that a large number of satisfactory people can be accommodated in that but the inappropriate design may lead due to catastrophic demolition or destruction of the structure which is obvious from the earlier few decades. Therefore the structures are susceptible to these catastrophic failures by a number of structural parameters due to its framed system and its own weight. Usually the multi-storied buildings are analysed using general one step linear static analysis assuming the full loads to be applied on the structure. But there may be lot of differences in the outcomes obtained from the analysis against practical aspect. Therefore to briefly understand and to overcome this problem a non-linear P-Delta analysis is performed for the structure. 


\section{International Journal of Science and Research (IJSR) \\ ISSN (Online): 2319-7064}

Index Copernicus Value (2013): 6.14 | Impact Factor (2015): 6.391

\subsection{Objective of Study}

The objective of the present work is to determine in what way the P-delta analysis influence the variation of responses of the structure such as bending moments, displacements and shear forces against linear static analysis. To perform the analysis ETABS2015 software is used for all models of each case. In order to understandthe trend of P-delta effects, the height of the building is gradually increased from story 5 to story 25 in 5 story intervals. After comparing the performance of RC structure with respect to displacement, shear and moment between two analysis mentioned above, necessity of P-delta analysis over linear static analysis will be understood clearly.

\section{Methodology}

As earlier stated, P-delta is a second order loading considering analysis which is required for structures consisting slender columns, slender structure as a whole, steel structure for preventing collapse and for heavy dead load consisting structures. But sometimes it is avoided because of complexity involved in this. The idea of this study evolve here and that is to show that slenderness changes with height and displacement varies unexpectedly with increasing slenderness. By controlling slenderness, the magnitude of P-delta effect can be neglectedin design; for instance at the structure level by use of heavier bracings and at the element level by increasing member size. Slenderness effects are extremely important in designing compression members.

It was decided that the best way to evaluate P-delta effects in tall buildings is simulating different cases by both P-delta analysis and linear static analysis. To vary the slenderness story height is changed. While changing the height a problem was faced that what will be the interval. It is really time consuming to conduct research and chose interval. To simplify the analysis the intervals chosen are 5,10,15,20 and 25, according to Yousuf Dinar et.al.

\section{Description of Models}

Five three dimensional building models are used as the basic models in the study. The buildings have 5, 10, 15, 20 and 25 stories. Bay length of buildings in each direction is $3 \mathrm{~m}$ and their typical storey height is $4 \mathrm{~m}$ and bottom storey height is $5 \mathrm{~m}$. The floors are assumed to be semi-rigid in their plane. The seismic lateral load is considered in both directions of the structure using IS 1893:2002 (Part - 1) by providing seismic coefficient of seismic zone 2 to perform both Linear static and P-Delta analysis separately. The beams are of same size of $300 \times 450 \mathrm{~mm}$ of M30 grade. The columns are of size $300 \times 600 \mathrm{~mm}$ for all positions and slab thickness is kept $150 \mathrm{~mm}$. The loads acting on the building other than earthquake loads has been provided as per IS 875 .

In the analysis of structures, neglecting the second order effects may overestimate the strength and stiffness of a member or a frame. The elastic forces generated within a member can be more accurately predicted with the use of an elastic second order analysis. The second order effects are of increasing importance as lighter and more flexible structures are constructed. The building model has been analysed for 5 to 25 storeys with 5 storey interval. The analysis has been carried out without P-Delta effect to locate maximum responses and then same has been analysed considering $\mathrm{P}$ delta effects. The maximum response values are compared to notify the P-delta effect.

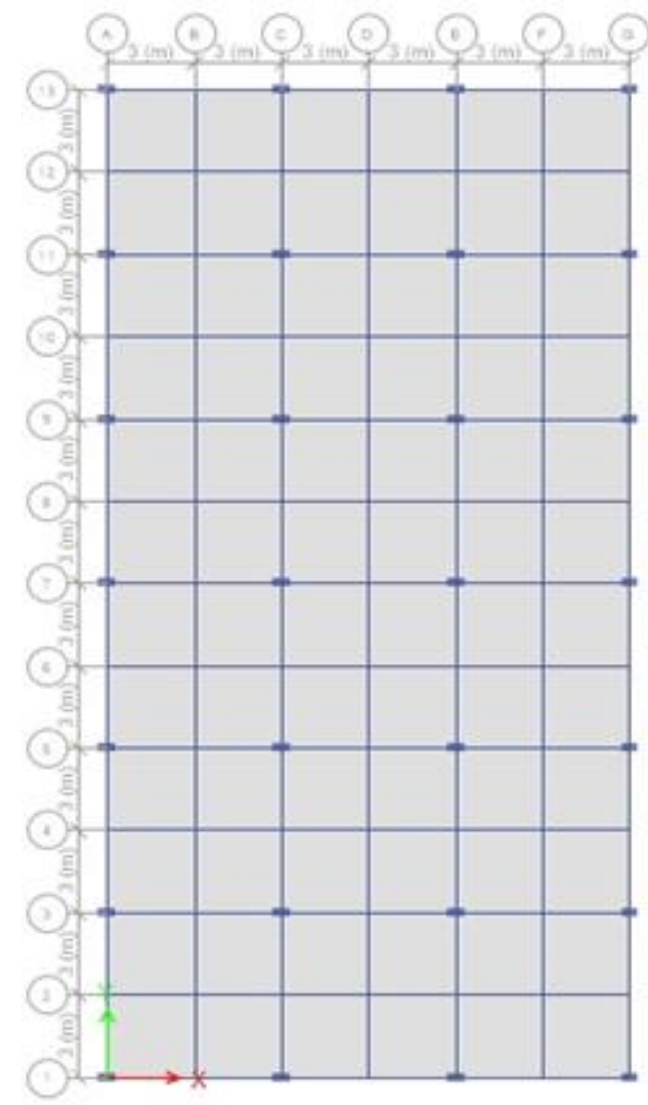

Figure 2: Plan of Building

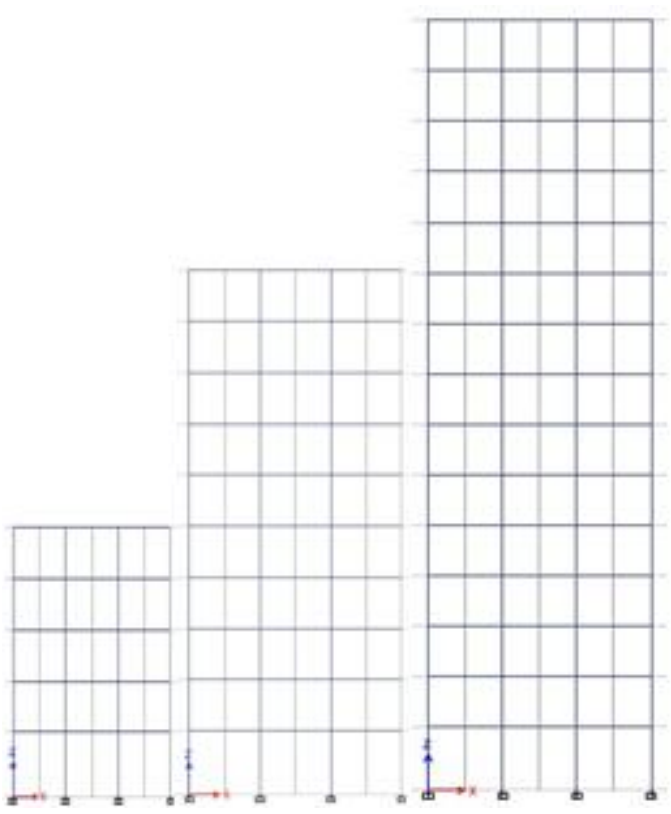




\section{International Journal of Science and Research (IJSR)
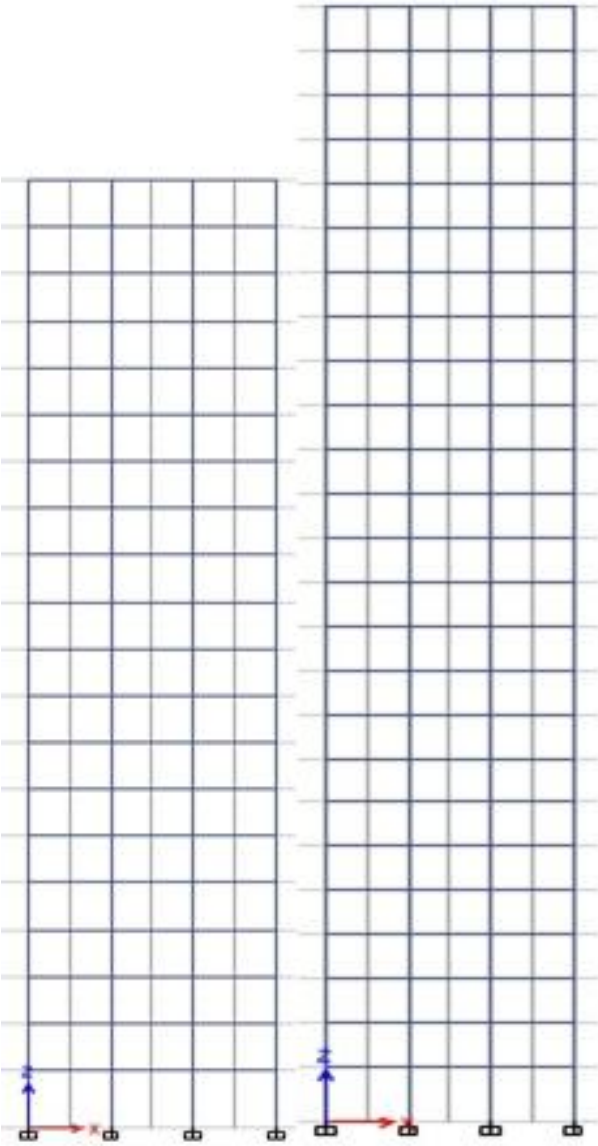

Figure 3: Three Dimensional Frame Models of Five Different Storeys

\section{Results and Discussions}

P-Delta and Linear static analysis of all the models reveals that P-Delta effects significantly influence the displacement and have higher value than linear static analysis. Results of all the different types of analysis such as linear static analysis and P-Delta analysis for reinforced concrete structures are obtained and mentioned here.

\subsection{Storey displacement of different storey cases:}

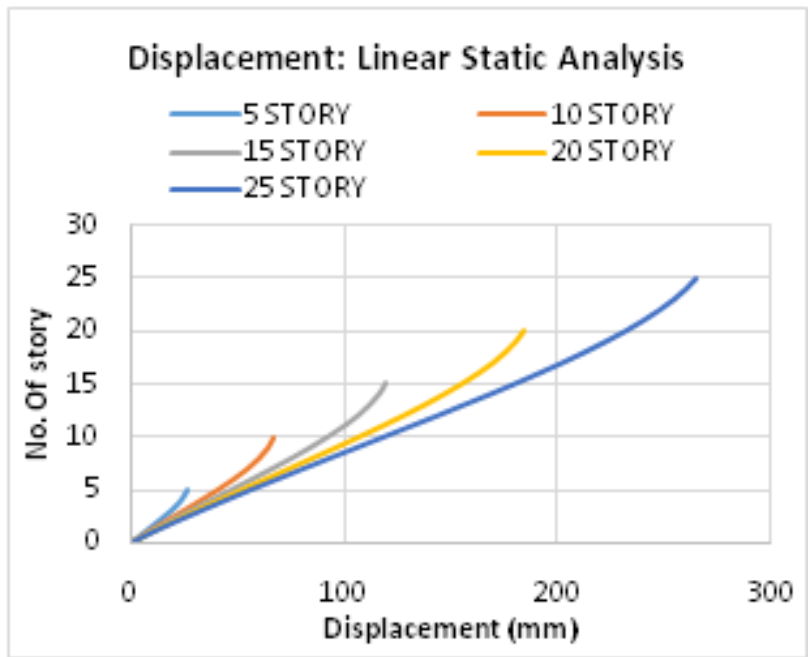

Figure 4: Storey displacement considered for five storey cases under consideration of linear static analysis.

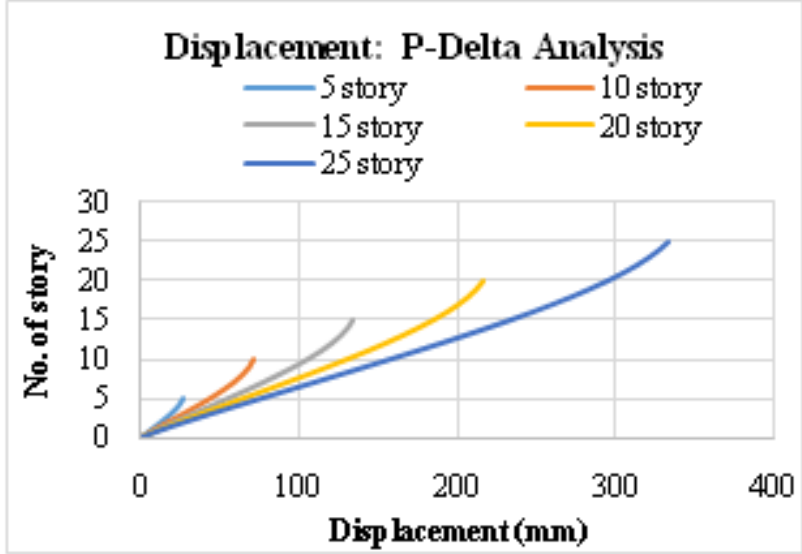

Figure 5: Storey displacement considered for five storey cases under consideration of P-Delta effects.

This phenomenon represent that linear static analysis considers only first order loading effects which is not realistic for tall slender structures. But P-delta analysis is suitable to get the iterative action as it consider second order loading effects after performing the first order effects. Maximum displacement is found in the top of the storey.

\subsection{Variation of horizontal displacement in top:}

All 10 models and 5 storey cases are studied to describe how the structure behave differently with height and obviously to present the priority of P-Delta analysis over Linearsttic analysis.

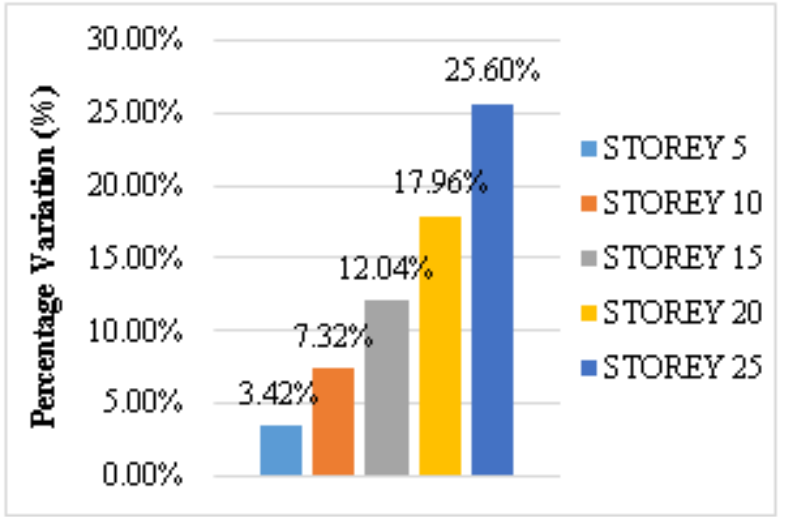

Figure 6: Percentage of variation of displacement in top considered under P-Delta analysis over Linear static analysis

It has been found that structure analysed under P-Delta effect causes much displacement in top than that analysed by Linear static analysis. The variation is following an upward trend with increasing storey.

\subsection{Storey Moment of Different cases:}

In order to study the P-Delta effects, storey moments of each storey with two different cases: Linear static analysis and PDelta analysis are observed. The moments are found to be decreasing with increment of height after consideration of $\mathrm{P}$ Delta effect. 


\section{International Journal of Science and Research (IJSR) \\ ISSN (Online): 2319-7064 \\ Index Copernicus Value (2013): 6.14 | Impact Factor (2015): 6.391}

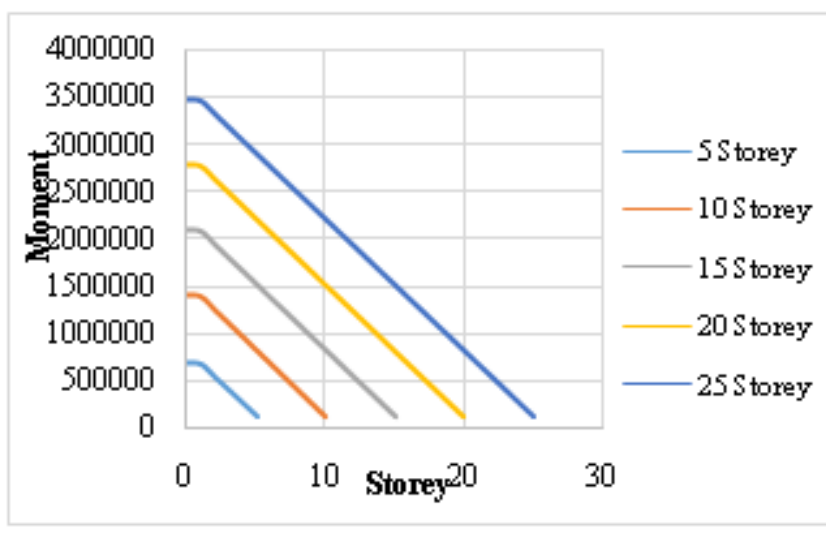

Figure 7: Storey moment for five storey cases for P-Delta

\section{Conclusion}

This paper presented the variation of displacement with increasing height, slenderness; considering P-Delta analysis keeping Linear static analysis as base. Variation of displacement for each case under two analysis procedure identified that displacement increases with increase in height, but it is more severe for P-Delta analysis. Moment shows different tendency which is decreasing in value with increment of storey. From the study what is inferred is that P-delta is essential for storeys higher than 15 storey. So linear static and P-Delta both are necessary for RC structures and have to use after proper understanding to prevent any catastrophic. All these outcomes were of reinforced concrete structure which is very common in society.

\section{Future Scope}

In coming days, studies should be done to observe how the bracing, infill, shear wall and composite section influence the effects of P-Delta. Like Linear static analysis other dynamic analysis could be simulate to suggest the designers the most suitable analysis for high rise structures with storey limit.

\section{References}

[1] Shah Mrugesh D., Desai Atul N, "Performance based on analysis of R.C.C. frames", National Conference on recent Trends in Engineering and technology,. V.M. engineering college, V.V Nagar, Gujarat, India.2011.

[2] Bulent N. Alemdar, "Modification to current P-delta implementation for rigid diaphragms", July2010.

[3] A.S. Moghdam and A. Aziminejad, "Interaction of torsion and P-delta effect in tall buildings",13th World conference on earthquake engineering, Vancouver, B.C., Canada, Aug1-6,paper no 799, 2009.

[4] Kadid A. and Boumrkik A., "Pushover analysis of reinforced concrete frame structures", Asian journal of civil engineering (buildings and housing) Vol. 9, pp. 7583,200

[5] Shah B.A, Patel P.V, "Seismic evaluation of RCC framed structures using static pushover analysis", International conference on recent trends in concrete technology and structures", Kumaraguru college of technology, Coimbatore, pp. 658-665, 2003.
[6] Richard Dobson-Technical director for FASTRAK ,and TEDDS CSC (UK) ltd, kennyArnott-product manager for S-frame ,CSC (UK) Ltd "Briefy overview of 2nd order (P-delta) Analysis.

[7] Yousufdinar,Nazzimuddinrahi,PronobDas,"Variation of deflection of steel High-Rise structure Due to P-delta effect considering Global Slenderness Ratio".

\section{Author Profile}

Saranya S Pillai, received the B.Tech. degree in Civil Engineering from St. Thomas College of Engineering and Technology in the year 2014. Presently doing Mtech at Sree Buddha College of Engineering. This work is presented as part of Mtech Thesis.

NamithaChandran, Assistant Professor at Sree Buddha College of Engineering, gave proper instructions and guidance for the successful completion of this topic. She had done her Btech and Mtech from Sree Buddha College of Engineering during the year 2012 and 2015. 